\title{
Diagnóstico diferencial de hernia discal
}

\author{
Marcelo Gálvez M.', Jorge Cordovez M.', Cecilia Okuma P.', Carlos Montoya M.', Takeshi Asahi K. ${ }^{2}$
}

1. Departamento por Imágenes Clínica Las Condes.

2. Laboratorio de Biomodelamiento Médico, Clínica Las Condes.

\section{Diagnostic differences for disc herniation}

\begin{abstract}
Disc herniation is a frequent pathology in the radiologist's daily practice. There are different pathologies that can simulate a herniated disc from the clinical and especially the imaging point of view that we should consider whenever we report a herniated disc. These lesions may originate from the vertebral body (osteophytes and metastases), the intervertebral disc (discal cyst), the intervertebral foramina (neurinomas), the interapophyseal joints (synovial cyst) and from the epidural space (hematoma and epidural abscess). Keywords: Herniated disc, Spondylosis, osteophyte, bone metastasis, discal cyst, neurinoma, synovial cyst, epidural hematoma, epidural abscess.
\end{abstract}

\section{Resumen}

La hernia discal es una patología frecuente en la práctica diaria del radiólogo. Hay distintas patologías que pueden simular una hernia discal desde el punto de vista clínico y especialmente imagenológico que debemos considerar cada vez que informamos una hernia discal. Estas lesiones pueden provenir del cuerpo vertebral (osteofitos y metástasis), del disco intervertebral (quiste discal), de los forámenes intervertebrales (neurinomas), de las articulaciones interapofisiarias (quiste sinovial) y desde el espacio epidural (hematoma y absceso epidural).

Palabras clave: Hernia discal, Espondilosis, osteofito, metástasis ósea, quiste discal, neurinoma, quiste sinovial, hematoma epidural, absceso epidural.

Gálvez M., et.al. Diagnóstico diferencias de hernia discal. Rev Chil Radiol 2017; 23(2): 66-76.

Correspondencia: Marcelo Gálvez / mgalvez@clc.cl

Trabajo recibido el 19 de junio de 2017. Aceptado para publicación el 21 de julio de 2017.

\section{Introducción}

La hernia discal es uno de los diagnósticos más frecuentes en la práctica radiológica de la patología de la columna vertebral. Sin embargo, debemos considerar en el diagnóstico diferencial otras patologías que pueden simular hernias discales, especialmente en algunas secuencias o planos al leer una resonancia magnética.

Las hernias discales, frecuentemente están en contacto con el disco intervertebral, se localizan en el espacio intrarraquídeo extradural. En algunas oportunidades pueden extenderse al foramen intervertebral o incluso en situación extraforaminal.
Pueden tener un componente ascendente o descendente, localizándose por detrás del cuerpo vertebral y ocupando el canal raquídeo central o los recesos laterales.

En las imágenes de tomografía computada se visualiza como una masa intrarraquídea extradural, adyacente e isodensa al disco intervertebral que ocupa en canal raquídeo o receso lateral desplazando el saco dural.

En las imágenes de resonancia magnética su apariencia es muy variable. Frecuentemente se visualizan como lesiones de baja señal en las imágenes ponderadas en T2 comparadas con los 
discos intervertebrales, pero pueden ser isointensa o hiperintensas respecto del disco intervertebral lo cual dificulta su visualización en imágenes convencionales de resonancia magnética.

Luego de la administración del medio de contraste, generalmente presentan captación periférica, en aspecto de "huevo frito".

El diagnóstico diferencial de la hernia discal lo debemos hacer con otras lesiones que, aunque menos frecuentes, pueden llevarnos a un diagnóstico erróneo.

Estas lesiones pueden originarse en las estructures vecinas como el cuerpo vertebral, disco intervertebral, foramen intervertebral, articulación interapofisiaria o del espacio epidural.

Consideraremos que las lesiones que se pueden originar del cuerpo vertebral son los osteofitos y las metástasis; desde el disco intervertebral el quiste

Tabla 1. Clasificación de las patologías a considerar en el diagnóstico diferencial de las hernias discales según su lugar de origen

\begin{tabular}{|l|}
\hline A. Cuerpo vertebral \\
\hline Osteofitos \\
\hline Metástasis \\
\hline B. Disco intervertebral \\
\hline Quiste discal \\
\hline C. Foramen intervertebral \\
\hline Neurinoma \\
\hline D. Articulación interapofisiaria \\
\hline Quiste sinovial \\
\hline E. Espacio epidural \\
\hline Hematoma epidural \\
\hline Absceso epidural \\
\hline
\end{tabular}

discal; de los forámenes intervertebrales los neurinomas; de las articulaciones interapofisiarias hacia los recesos laterales el quiste sinovial; $y$ desde el espacio epidural, el hematoma y el absceso epidural (Tabla 1).

\section{A. Cuerpo vertebral 1. Osteofitos}

La espondilosis se define como un proceso no inflamatorio que ocurre principalmente debido a la degeneración del disco intervertebral. La degeneración del disco y el desarrollo de la espondilosis forman parte del proceso normal de envejecimiento.

La presencia de osteofitos es muy frecuente, afectando predominantemente a los adultos, su incidencia aumenta con la edad, observándose hasta en el $80 \%$ de los pacientes de 75 años ${ }^{1}$.

Estos cambios degenerativos tienen el potencial de disminuir la amplitud del canal raquídeo y eventualmente comprimir los elementos neurales, produciendo mielopatía o neuropatía ${ }^{2}$.

Los osteofitos que se dirigen hacia posterior pueden comprimir la médula espinal o la emergencia de las raíces nerviosas ventrales. Cuanto los osteofitos se dirigen hacia los forámenes intervertebrales pueden determinar compresiones radiculares (Figuras 1 a y b).

Los osteofitos son fácilmente visibles en las radiografías simples, especialmente en proyección lateral (Figura 2). El estudio de elección para visualizar los osteofitos a nivel de la columna vertebral y su relación tridimensional con las otras estructuras es la tomografía computada que nos permite una adecuada visualización de la amplitud del canal central, recesos laterales y forámenes intervertebrales.

En las imágenes de resonancia magnética los osteofitos aparecen de baja intensidad de señal en todas las secuencias (Figura 3). Muchas veces en las imágenes de resonancia magnética, especialmente en las de la columna cervical, es muy difícil diferenciar la hernia discal de un osteofito prominente, para lo cual debemos complementar el estudio con tomografía computada. Esta diferenciación es fundamental en el momento de la cirugía, ya que es totalmente diferente la resección de una estructura blanda como un disco intervertebral de una estructura muy densa como un osteofito, especialmente a nivel de un foramen intervertebral.

Cada vez que visualicemos una hernia discal hay que preguntarse si existe una proliferación ósea asociada.

\section{Metástasis}

La columna vertebral es el sitio óseo más común de localización de implantes secundarios ${ }^{3}$, y la tercera localización después de los implantes secundarios pulmonares y hepáticos. Los implantes secundarios pueden ser el primer signo de enfermedad neoplásica y pueden comprometer cualquier localización en la columna vertebral como en los cuerpos vertebrales, espacio epidural (Figuras 4a y b), leptomeninges o menos frecuentemente en la médula espinal ${ }^{4}$.

Las neoplasias de mama, próstata, tiroides, riñón y pulmón son tumores primarios más comúnmente asociados a las metástasis óseas.

El estudio de elección es la resonancia magnética, por sus propiedades múltiplanares y diferentes secuencias.

Las lesiones focales óseas aparecen frecuentemente hipointensas en secuencias ponderadas en T1 e hiperintensas en las secuencias ponderadas en T2. Ocasionalmente pueden tener un borde hipointenso T2 en la periferia de la lesión conocido como el "signos del halo". 
$1 a$.

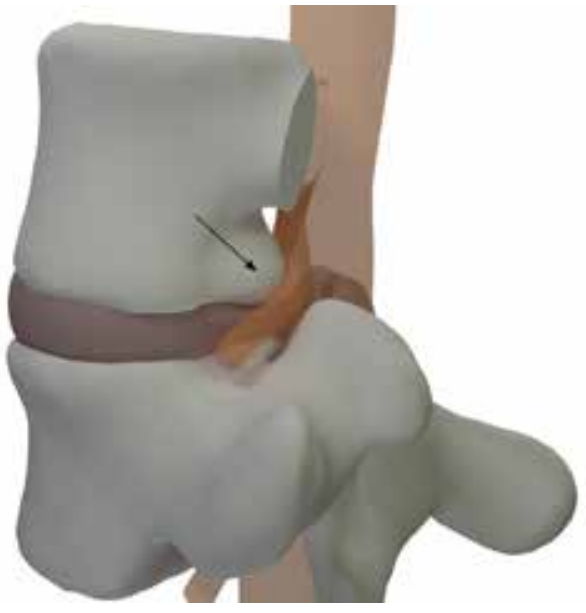

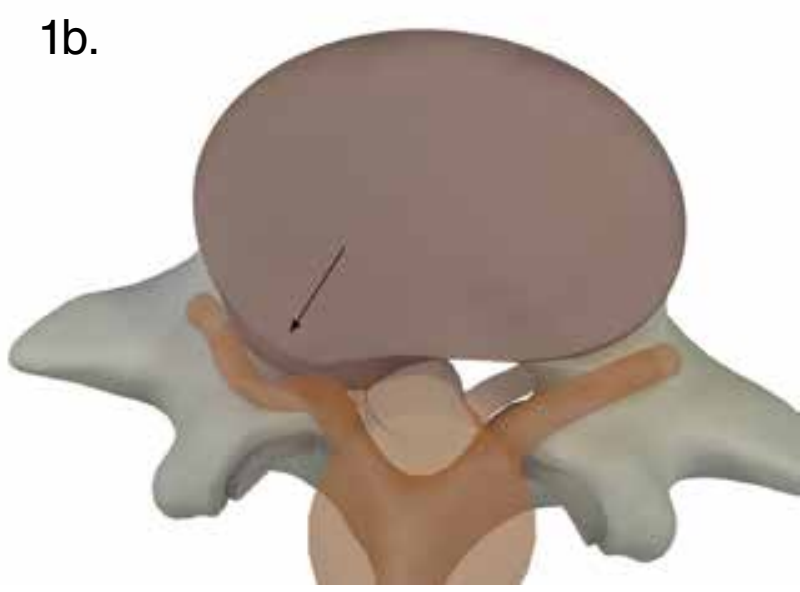

Figura 1. Representación de un osteofito posterolateral y foraminal derecho que junto a una protrusión del disco produce un desplazamiento de la raíz emergente. En la vista lateral (1a) se observa desplazamiento posterior de la raíz (flecha). En la vista superior (1b) se observa componente discal participante (flecha).

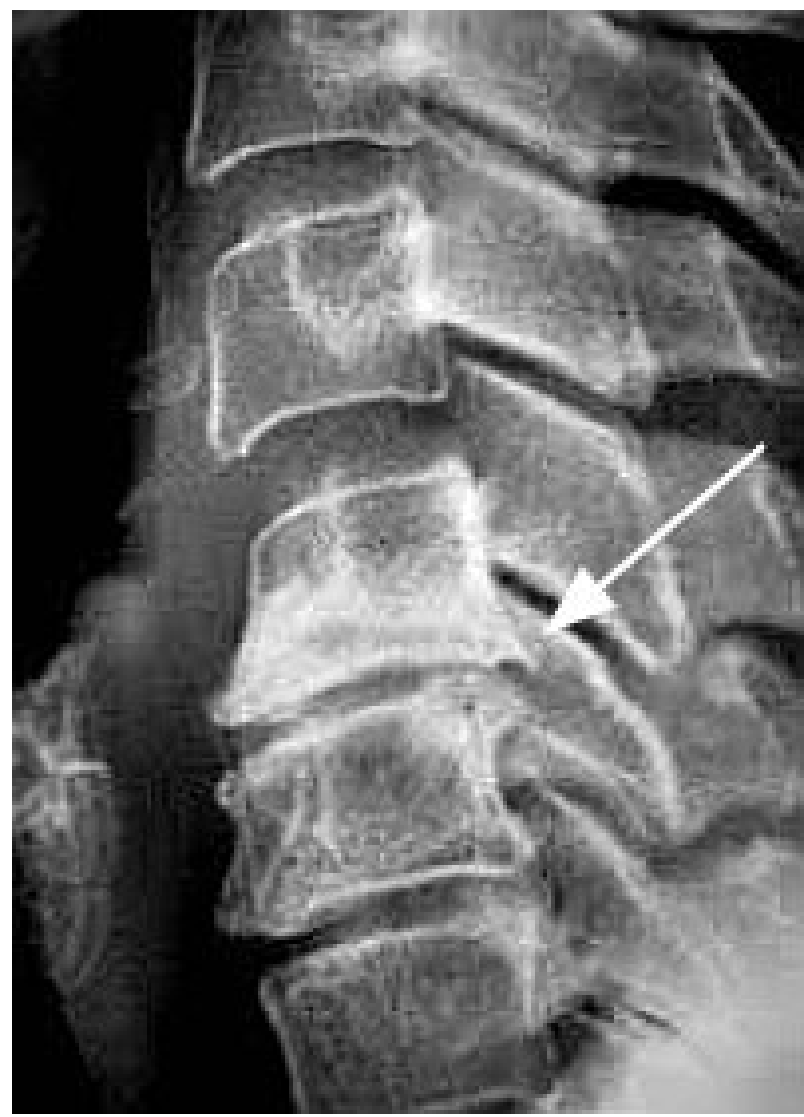

Figura 2. Radiografía lateral de la columna cervical que muestra osteofitos posteriores (flecha) que en resonancia magnética similar completamente una hernia discal.

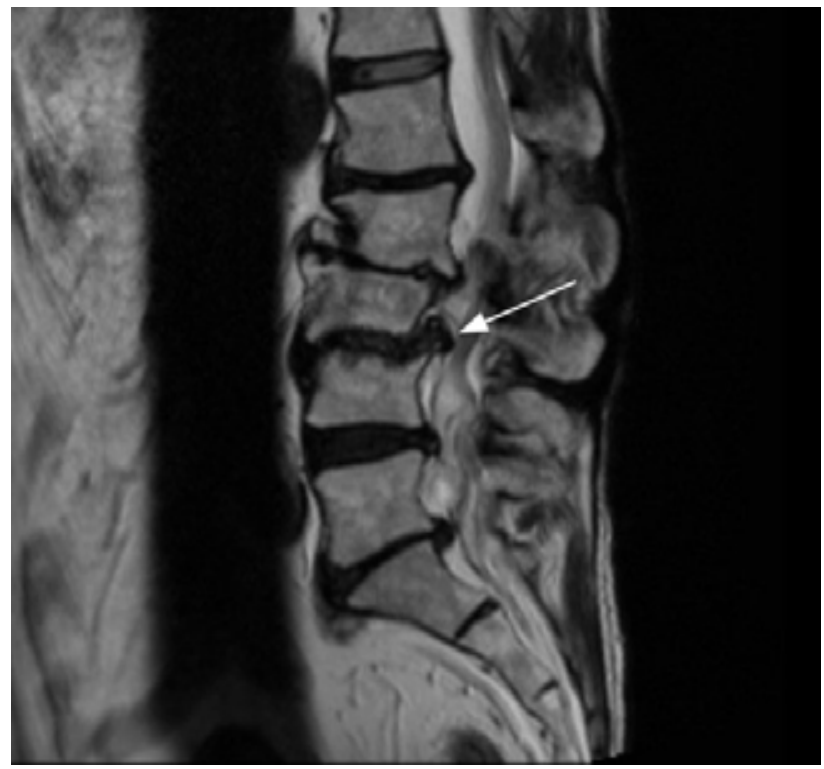

Figura 3. Imagen sagital de resonancia magnética ponderada en T2. se observa anterolistesis de L3. Un osteofito y material discal posterior (flecha) que disminuyen la amplitud del canal raquídeo. 

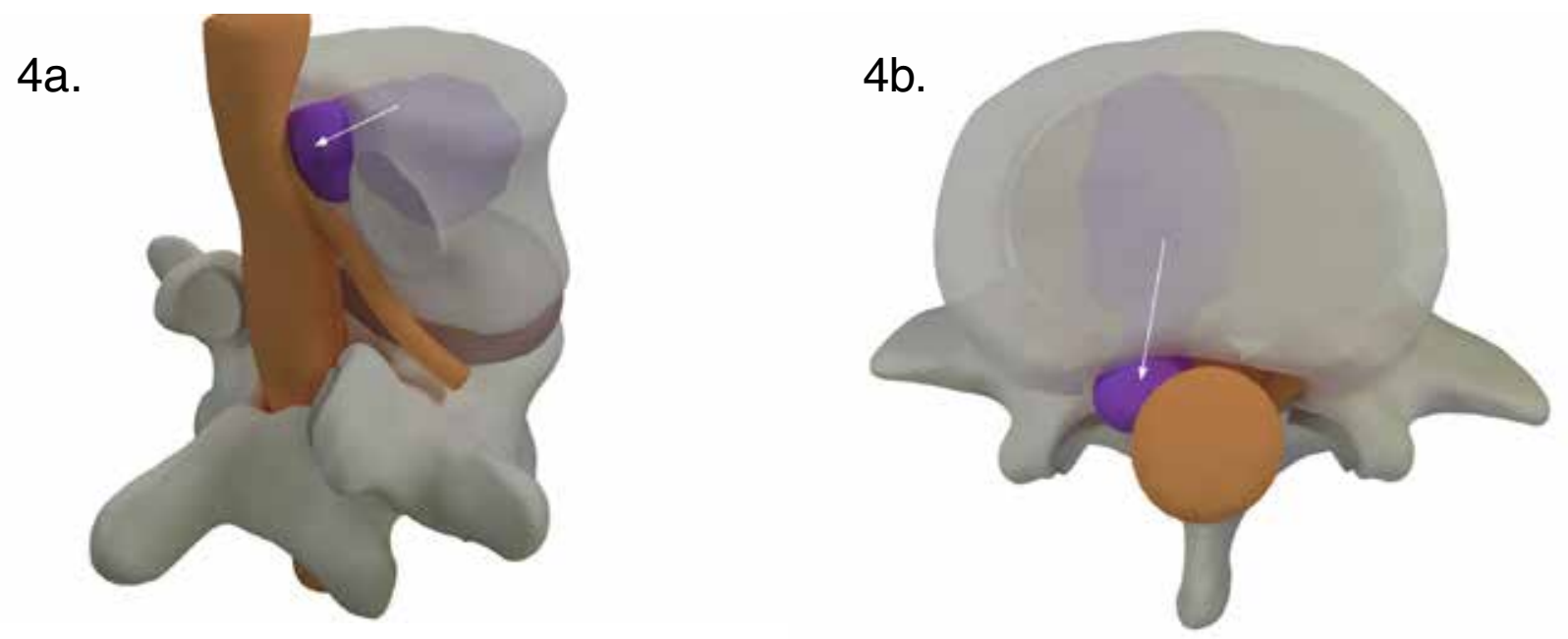

Figura 4. Representación de una metástasis del cuerpo vertebral superior que rompe la cortical posterior del cuerpo vertebral y se extiende al espacio epidural anterior por debajo del nivel del disco (no representado). Estas lesiones pueden fácilmente simular una hernia discal. En la vista posterolateral izquierda (4a) se observa compresión de la raíz a nivel de su origen (flecha). En la vista superior (4b) se visualiza por transparencia el tumor en el interior del cuerpo y su extensión epidural anterior (flecha).

Son de gran importancia las secuencias con saturación grasa como STIR, debido a que en las imágenes T2 TSE o FSE muchas de estas lesiones son indiferenciables de la médula ósea normal.

Las lesiones escleróticas aparecen hipointensas en las secuencias T1, T2 y T2 gradiente. La señal de médula ósea puede ser difusamente anormal. Las imágenes T1 con saturación grasa y contraste paramagnético permiten delimitar la extensión de la lesión y compromiso de estructuras adyacentes como el espacio epidural, foramen intervertebral y región paraespinal.

El espacio epidural puede ser una localización primaria de la enfermedad neoplásica, pero más frecuentemente corresponde a una extensión extraósea de una metástasis del cuerpo vertebral o arco posterior (Figura 5).

En el espacio epidural puede simular una hernia discal y ejercer efecto de masa sobre la médula espinal y las raíces nerviosas. En el foramen intervertebral puede simular una hernia discal foraminal (Figura 6).

Desde el espacio epidural la lesión se puede diseminar a los cuerpos vertebrales adyacentes por vía venosa.

\section{B. Disco intervertebral \\ 3. Quiste discal}

El quiste discal es una lesión muy poco frecuente y causa dolor lumbar y/o radicular. Su historia natural y manejo son poco conocidos 5 .

En 1997 Toyama $^{6}$ utiliza este término para describir una imagen quística epidural anterior en relación al disco intervertebral que se impregna en su periferia post gadolinio endovenoso.
Kono en $1999^{7}$, describió un quiste intraespinal extradural bien definido, homogéneo, de localización ventrolateral, con desplazamiento del saco dural y comunicación con el disco intervertebral (Figuras 7 a y b)

El quiste discal fue definido como una entidad por Chiba el $2001^{8}$. Describe la presentación clínica, características en las imágenes y los hallazgos histopatológicos de los quistes discales.

La resonancia magnética demuestra una lesión esférica de baja señal en las imágenes ponderadas en T1 y alta señal en las imágenes ponderadas en T2, consistente con una lesión quística de contenido líquido, totalmente diferente del contenido observado en pacientes con hernia discal (Figuras 8 y 9). El grado de degeneración discal es generalmente leve, con mínima perdida de la señal del núcleo discal ${ }^{9}$, consistente con los hallazgos de la discografía.

El 2006, Lee et al..$^{10}$ dio detalles de las características del quiste discal: 1) Quiste extradural ventrolateral anclado al disco lumbar. 2) Anillo de refuerzo con contraste en la resonancia magnética y 3 ) Extensión ocasional en el receso lateral. La discografía y la CT discografía demuestran un canal entre el quiste y el disco, diferenciando éste con una hernia discal u otro quiste intraespinal.

La patogénesis del quiste discal es poco clara. Se plantea la reabsorción de una hernia discal prexistente y un hematoma asociado con el prolapso discal.

Tokunaga et al. ${ }^{11}$. Confirmó la presencia de tejido cartilaginoso en la pared del quiste y se piensa que el quiste discal pudo surgir de la reabsorción de una herniación discal. Chiba ${ }^{8}$ propone que el quiste discal surge desde un daño subyacente del disco intervertebral que causa una fisura del anillo fibroso en la 


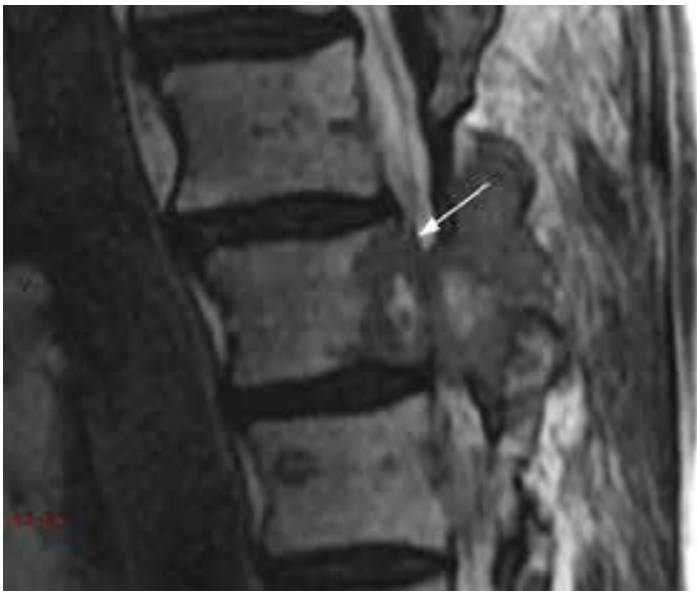

Figura 5. Imagen sagital de resonancia magnética ponderada e T2 que muestra una lesión ósea de la región posterior del cuerpo vertebral y extensión epidural anterior (flecha) que se localiza por detrás del cuerpo vertebral, adyacente al disco intervertebral inferior que puede simular una hernia discal.

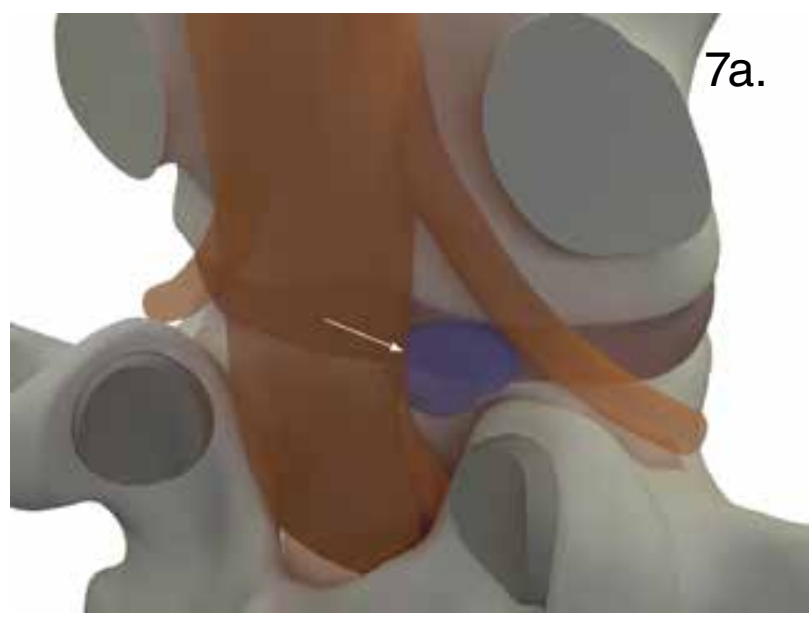

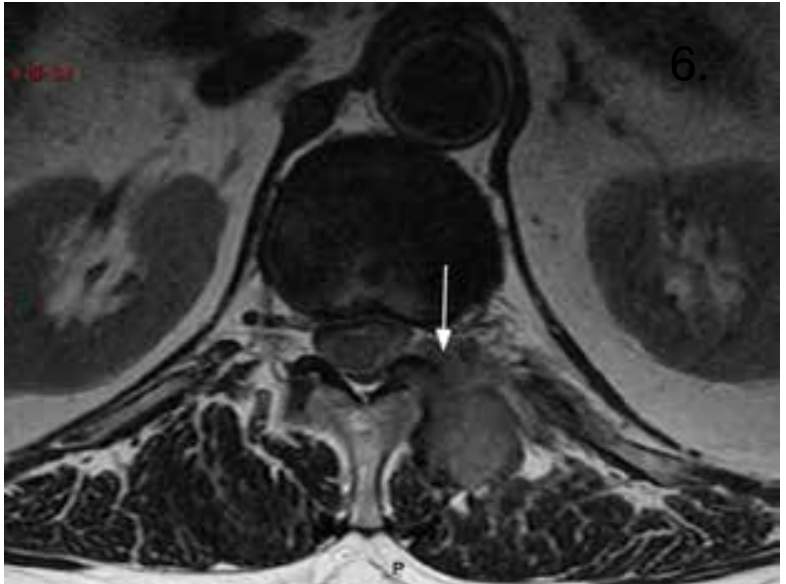

Figura 6. Imagen transversal de resonancia magnética ponderada en T2 que muestra una masa en el foramen intervertebral izquierdo (flecha) que procede de una masa ósea del pedículos y carillas articulares izquierdas. Clínicamente pueden parecer completamente al cuadro de una hernia discal.

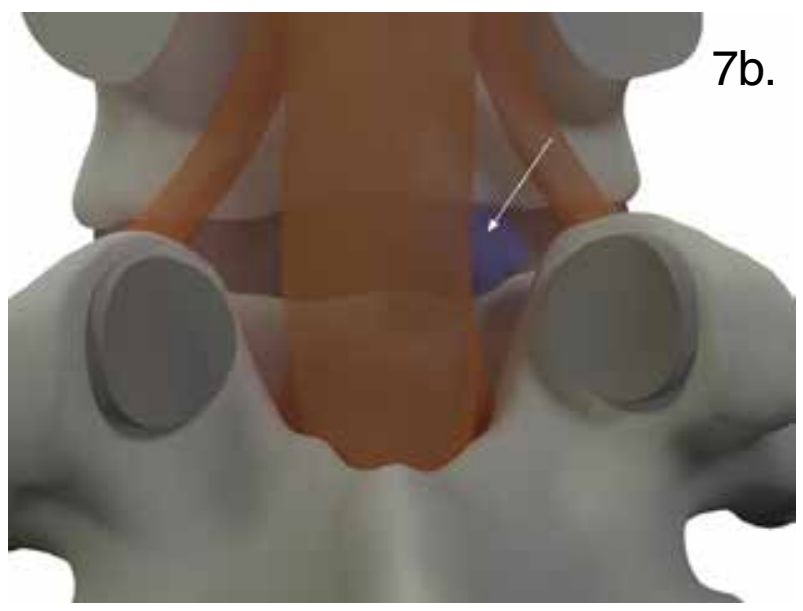

Figura 7. Representación de un quiste discal posterolateral derecho, como una lesión quística azul adyacente al disco intervertebral que protruye al espacio epidural y deforma el saco dural y origen de la raíz derecho subyacente. En la vista posterolateral derecha (7a) se observa que el quiste deforma el saco dural y el origen de la raíz subyacente (flecha). En la vista posterior (7b) se observa que el quiste se encuentra a nivel del disco (flecha).

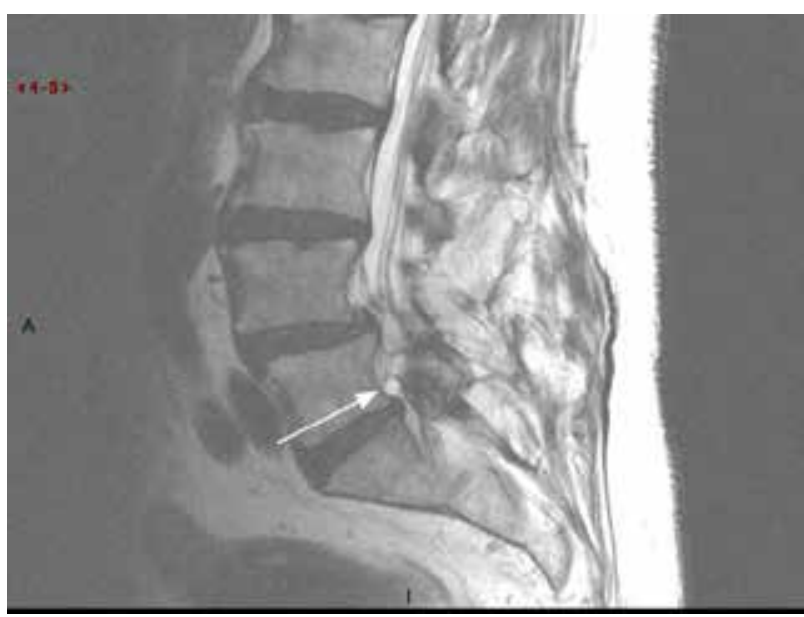

Figura 8. Imagen sagital de resonancia magnética ponderada en T2 que muestra un pequeño quiste discal (flecha) posterolateral derecho, inmediatamente por sobre el disco intervertebral.

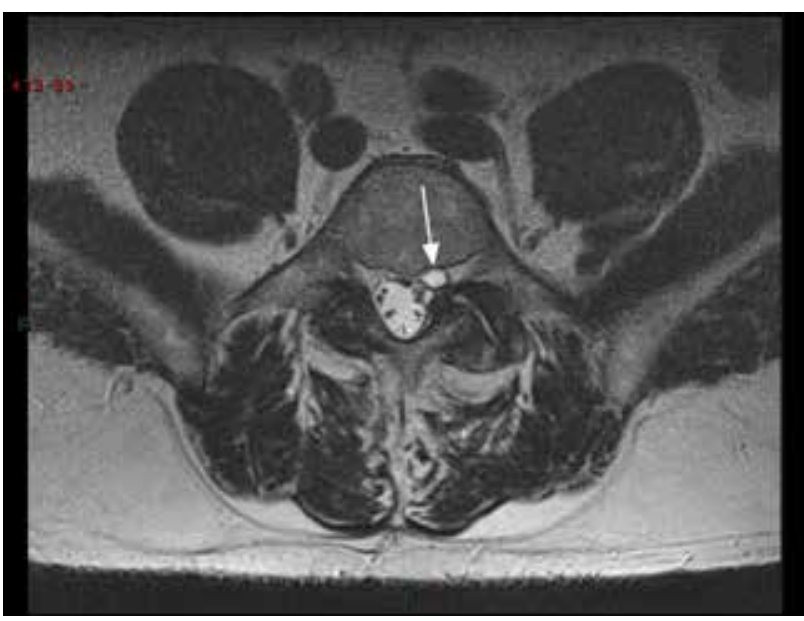

Figura 9. Imagen transversal potenciada en T2 que muestra un pequeño quiste discal (flecha) posterolateral izquierdo que contacta el saco dural. 
región posterior del disco intervertebral. Los estudios patológicos muestran tejido conectivo fibroso con depósitos de hemosiderina en las paredes del quiste 5 .

\section{Foramen intervertebral}

\section{Neurinoma}

Los neurinomas (Schwannomas) son comúnmente lesiones neoplásicas benignas que representan Aproximadamente un tercio de todos los tumores espinales primitivos ${ }^{12}$.

La edad promedio se encuentra en la cuarta década de la vida y son más frecuente en la región lumbosacra ${ }^{13}$.

Los neurinomas en los forámenes lumbosacros son también relativamente infrecuentes. Según estudios occidentales, la incidencia de los neurinomas espinales varía entre 0,3 y 0,5 / 100,000 personas por año, por lo que en nuestro país podríamos tener aproximadamente 70 casos al año.
Los neurinomas más frecuentes son los intradurales, seguidos por los extradurales y luego los intra y extradurales al mismo tiempo.

Los tumores tienen forma regular, ovalados (imagen 10 a y b) o en la forma de reloj de arena. Pueden tener una cápsula fina y con contenido quístico ${ }^{13}$.

Los neurinomas foraminales generalmente puede presentar ensanchamiento del foramen intervertebral.

Las hernias discales pueden llegar a parecer un neurinoma, en CT y RM, incluso con festoneado del cuerpo vertebral ${ }^{14}$.

El síntoma más frecuente corresponde a una radiculopatía, con dolor y parestesia. Se han descrito síntomas entre los 6 meses y 15 años, con una media de 5,5 años ${ }^{15}$.

La ausencia de un síntoma específico hace imposible diferenciar esta patología de una hernia

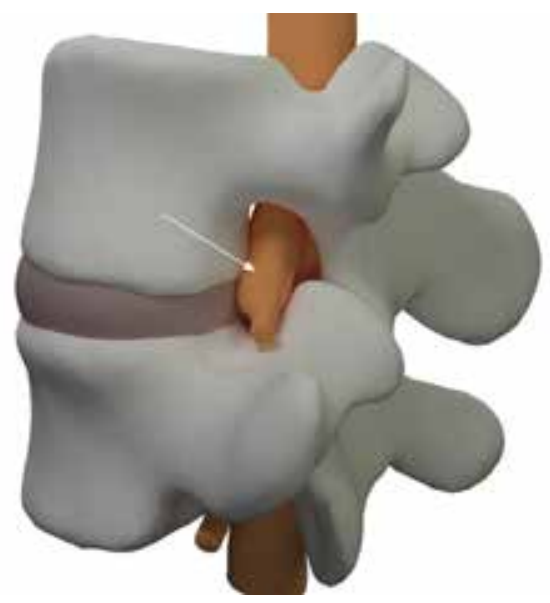

10a.

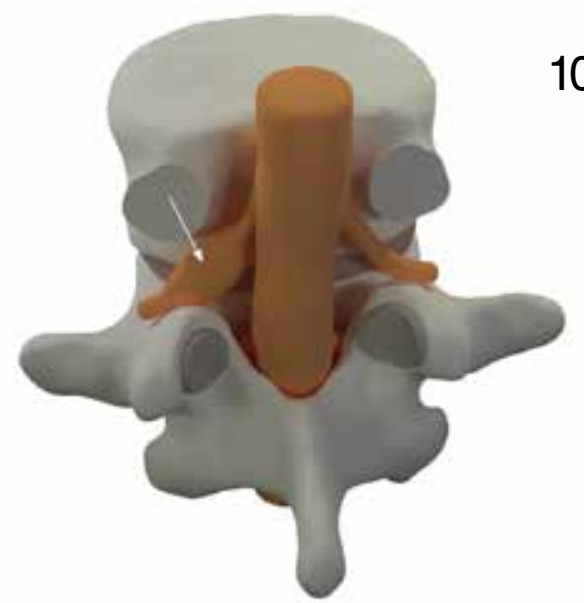

10b.

Figura 10. Representación de un neurinoma de la raíz izquierda emergente en la parte baja del foramen. Esta lesión puede simular una hernia discal foraminal. En la vista lateral izquierda (10a) se visualiza que la masa dependiente de la raíz contacta el disco intervertebral (flecha). En la vista posterior (10b) se observa claramente su origen radicular (flecha).

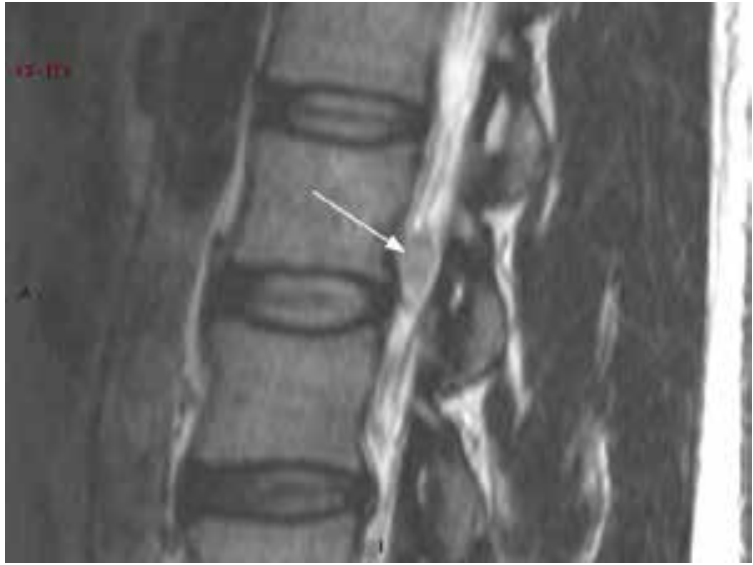

Figura 11. Imagen sagital de resonancia magnética ponderada en T2 que muestra una pequeña masa redondeada hiperintensa, intrarraquídea, posterolateral al cuerpo vertebral (flecha) que corresponde a un neurinoma.

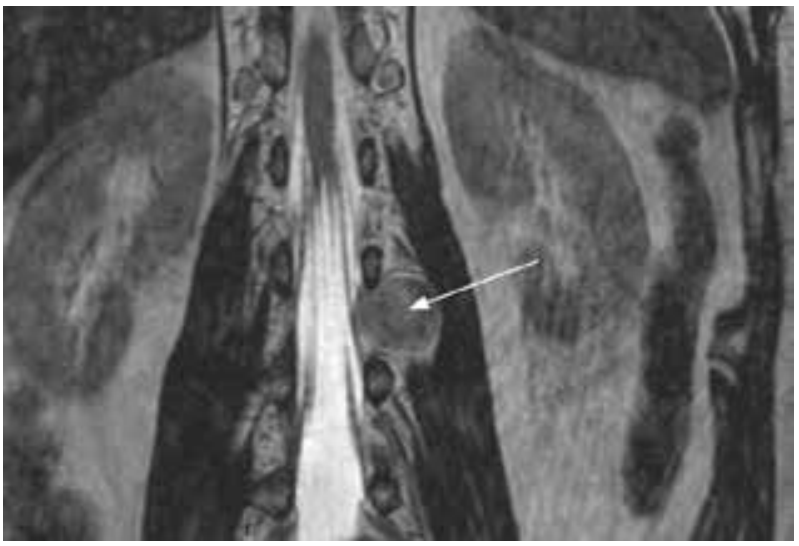

Figura 12. Imagen coronal potenciada en T2 que muestra una masa posterolateral, foraminal y extraforaminal izquierda (flecha) que ocupa prácticamente todo al foramen y contacta la raíz subyacente. 
discal desde el punto de vista clínico ${ }^{15}$.

En tomografía computada se observan como tumores bien definidos, más bien homogéneos con ensanchamiento del foramen vertebral. La tomografía computada no siempre puede diferenciar el neurinoma de una hernia discal' ${ }^{15}$.

La resonancia magnética muestra que la lesión presenta alta señal en T2 (Figura 11) y se impregna con gadolinio en forma homogénea. Las imágenes de $\mathrm{RM}$ en los planos sagital y coronal son muy útiles para evaluar la relación entre tumor y disco, y la extensión del tumor en el foramen intervertebral (Figura 12) ${ }^{15}$.

Ocasionalmente la tomografía computada y resonancia magnética de las hernias discales pueden simular a un tumor o un quiste ${ }^{16}$.

El tratamiento es quirúrgico con la resección del tumor sintomático.

\section{Articulación interapofisiaria \\ 5. Quiste sinovial}

Los quistes sinoviales, quistes juxtafacetarios o quistes ganglionares son relativamente raros y corresponden a una proliferación de la sinovial en la proximidad de la articulación interapofisiaria (Figuras 13 a y b) que fue primero descrita por Baker en el año $1885^{17}$.

Solamente a partir de 1950 se describió que podrían ser la causa de radiculopatía ${ }^{18}$.

Los reportes de quistes sinoviales han aumentado en la literatura internacional ${ }^{19}$, posiblemente por el avance de las técnicas imagenológicas.

Los pacientes frecuentemente se encuentran en

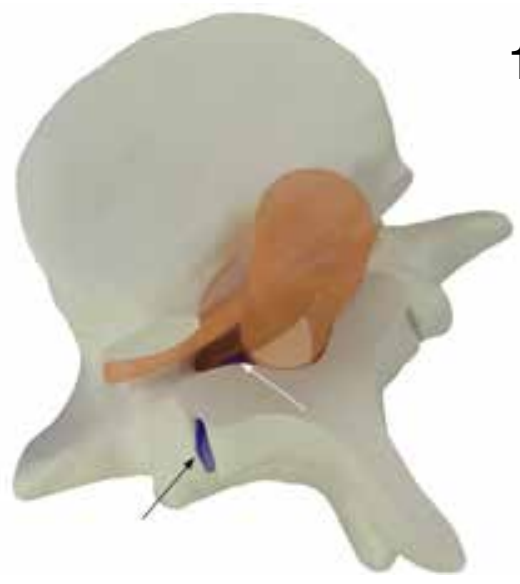

$13 a$.

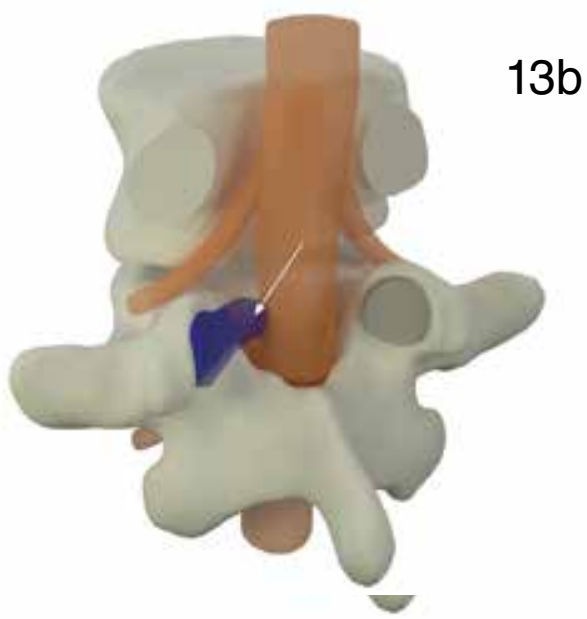

Figura 13. Representación de un quiste sinovial que se origina desde la articulación interapofisiaria izquierda y que se extiende hacia anterior contactando el saco dural. En la vista posterior (13a) se observa que se origina desde la articulación interapofisiaria (flecha negra) y se extiende al espacio epidural posterior (flecha blanca). En la vista posterolateral izquierda (13b) sin carillas superiores se visualiza que el quiste se extiende hacia anterior deformando el saco dural (flecha).

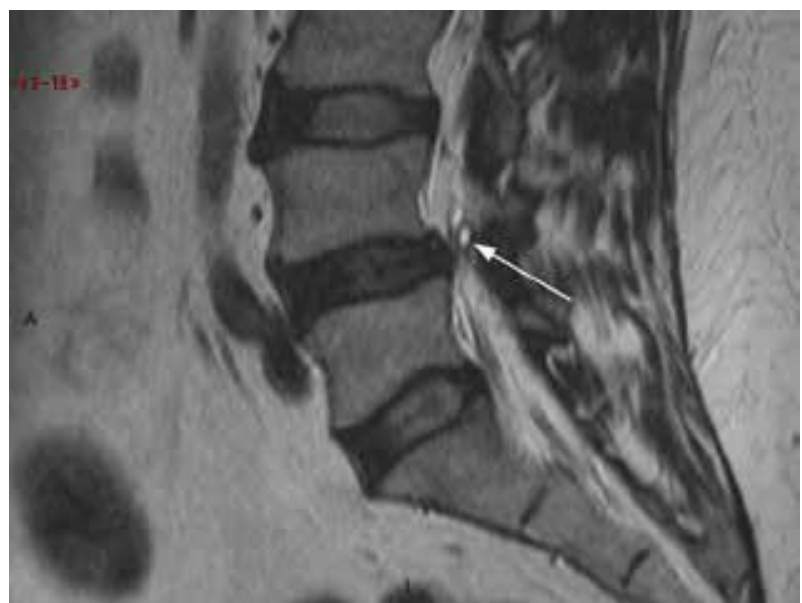

Figura 14. Imagen sagital de resonancia magnética potenciada en T2 que muestra un pequeño quiste sinovial (flecha) anterior adyacente a la articulación interapofisiaria L4-L5.

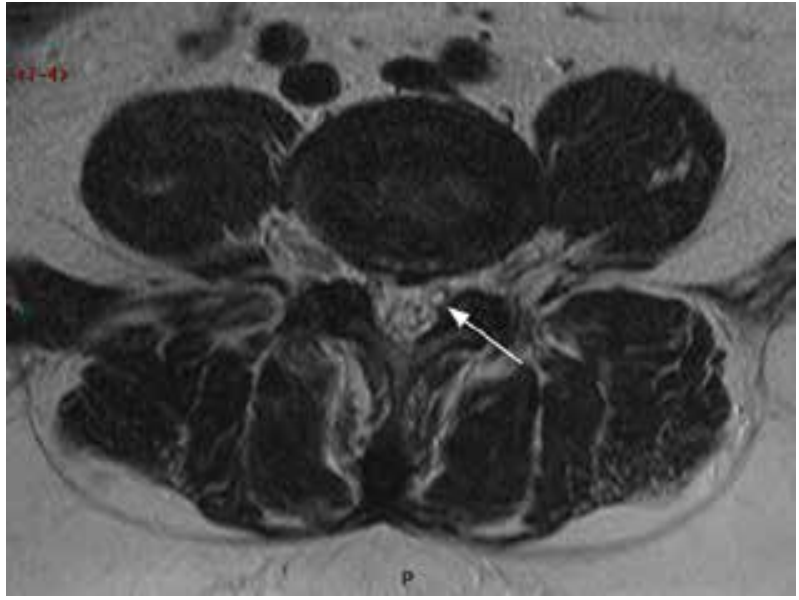

Figura 15. Imagen transversal potenciada en T2 que muestra pequeño quiste sinovial anterior (flecha) que ocupa el receso lateral izquierdo y comprime la raíz subyacente a nivel del receso lateral. 
la sexta década de vida, con leve predominio de las mujeres. Rara vez se detectan antes de los 30 años de edad ${ }^{20}$.

Pueden ser asintomáticos y encontrados incidentalmente. Sin embargo, si aumentan de tamaño pueden causar compresión de las estructuras neurales y síntomas secundarios ${ }^{21}$.

Los síntomas más frecuentes son dolor radicular y déficit neurológico de un territorio específico. Se cree que su incidencia es de menos del $0,5 \%$ de los pacientes con estos síntomas.

El nivel más frecuente corresponde al nivel L4-L5, ya que es el sitio con máxima movilidad (Figura 14). Los quistes pueden ser uni o bilaterales, y encontrarse en más de un nivel.

Se supone que los quistes se originan y comúnmente se encuentra comunicados con la articulación interapofisiari22.

Los quistes se pueden extender desde la articulación interapofisiaria hacia anterior, al canal raquídeo (Figura 15), o hacia posterior, a las partes blandas periarticulares. Los quistes posteriores son tres veces más frecuentes que los anteriores. Los quistes anteriores en un $70 \%$ de los casos se asocia a radiculopatía ${ }^{23}$.

Su etiología aún no está clara, sin embargo, la inestabilidad focal, la espondiloartrosis y la espondilolistesis tiene una fuerte asociación con la formación de los quistes sinoviales. Se describe también que los traumatismos articulares pueden estar relacionados a la formación de quistes ${ }^{22}$. Aunque también se han descrito en pacientes con artritis reumatoide y enfermedad por depósito de pirofosfato de calcio ${ }^{24}$.

La tomografía computada y en especial la resonancia magnética permiten hacer un diagnóstico adecuado de este tipo de lesiones ${ }^{25}$.
La resonancia magnética es considerada la herramienta de elección para el diagnóstico.

Los quistes frecuentemente son isointensos al líquido cefalorraquídeo en las imágenes ponderadas en $\mathrm{T} 1$ y $\mathrm{T}^{26}$.

En algunas oportunidades puede tener alta señal en las imágenes ponderadas en T1 y baja señal en las imágenes ponderadas en T2, debido a la presencia de un contenido hemorrágico o proteínico ${ }^{27}$.

En las imágenes ponderadas en T2 puede observarse un borde hipointenso, que puede corresponder a una calcificación, fibrosis o hemosiderina ${ }^{26}$.

El tratamiento puede ser percutáneo, con la inyección de líquido, anestésico o corticoide. En los casos resistentes a la terapia conservadora se puede pensar en tratamiento quirúrgico para la descompresión radicular. Sin embargo, puede existir recidiva de los quistes sinoviales, incluso después del tratamiento quirúrgico.

\section{E. Espacio epidural \\ 6. Hematoma epidural}

El hematoma epidural espinal es una colección hemática intrarraquídea extradural (Figuras 16 a y b) relativamente infrecuente que fue descrita en 1869 por Jackson ${ }^{28}$.

Las causas son múltiples, pudiéndose establecer su etiología en aproximadamente el $70 \%$ de los $\operatorname{casos}^{29}$.

Se han reconocido factores que favorecen la formación de hematomas epidurales, como las coagulopatías, trauma, punción lumbar y embarazo.

La edad promedio es de aproximadamente 50 años, pero pueden presentarse a cualquier edad, y suelen ser más frecuente en los hombres ${ }^{29}$.

Las localizaciones más frecuentes de los hematomas epidurales correspondieron a C6 (31\%) y
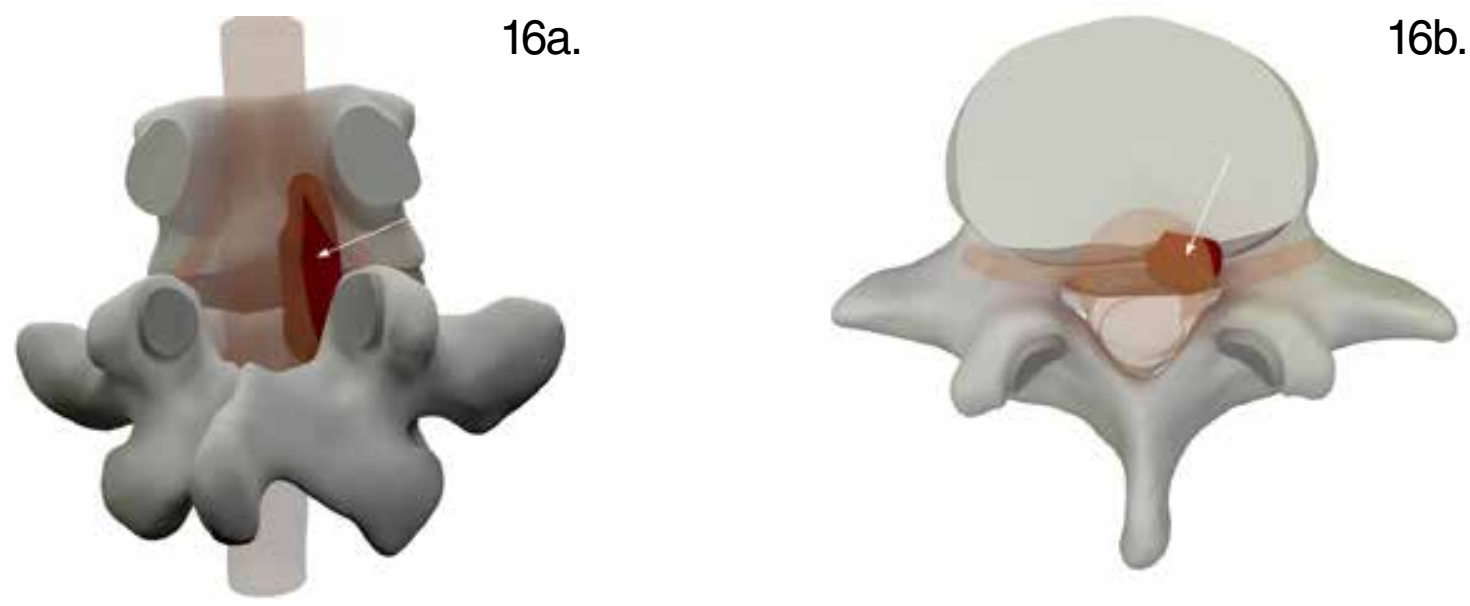

Figura 16. Representación de un hematoma epidural anterior, lateralizado a derecha. En la vista posterior (16a) se observa que el hematoma se extiende más allá del disco intervertebral (flecha), alcanzando el nivel del cuerpo superior e inferior. En la vista superior (16b) deforma el saco dural y la raíz a nivel de su nacimiento (flecha) por su localización. 
D12 (22\%), con una extensión máxima de 6 cuerpos vertebrales ${ }^{29}$.

Al momento del diagnóstico los pacientes presentan un trastorno neurológico moderado y sólo en algunos casos de hematomas epidurales lumbares los pacientes estaban asintomáticos.

La herramienta de elección es la resonancia magnética de columna, en especial las imágenes ponderadas en T1 y T2 que permiten demostrar la presencia de una colección intrarraquídea, extradural, especialmente por detrás de los cuerpos vertebrales (Figuras 17 y 18).

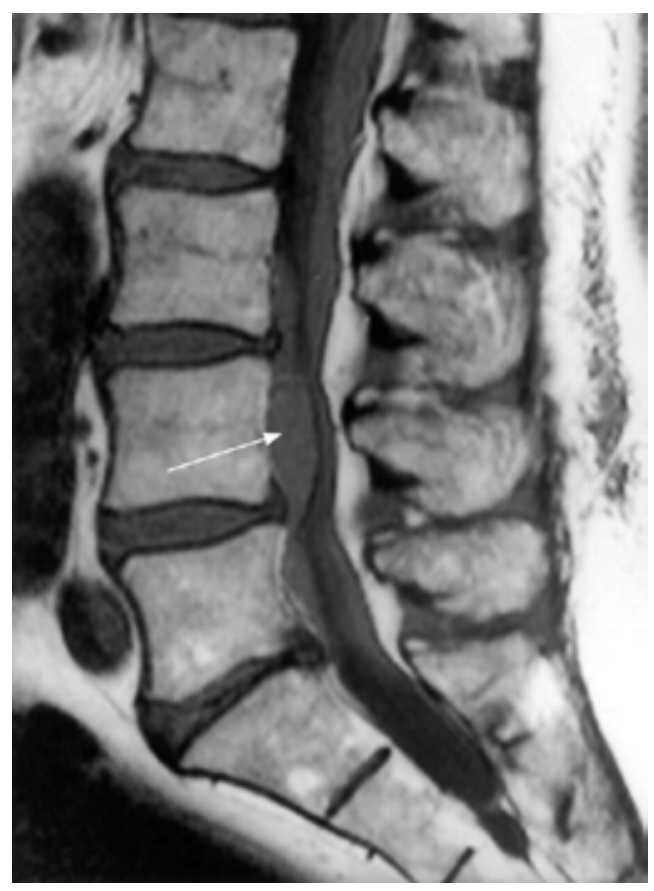

Figura 17. Imagen sagital ponderada en T1 que muestra una colección epidural anterior, ligeramente hiperintensa que se localiza por detrás de los cuerpos vertebrales L3, L4 y L5 (flecha).
En los casos de trauma vertebral se debe descartar dirigidamente la presencia de un hematoma epidural, que puede ser de muy difícil diagnóstico ${ }^{30}$.

El tratamiento de elección del hematoma epidural es la cirugía, y sus resultados están influenciados por las características clínicas y neurológicas del paciente; y estado general al ingreso, edad y extensión cráneo-caudal.

\section{Absceso epidural.}

El absceso epidural es una colección intrarraquídea extradural puede simular clínicamente el dolor

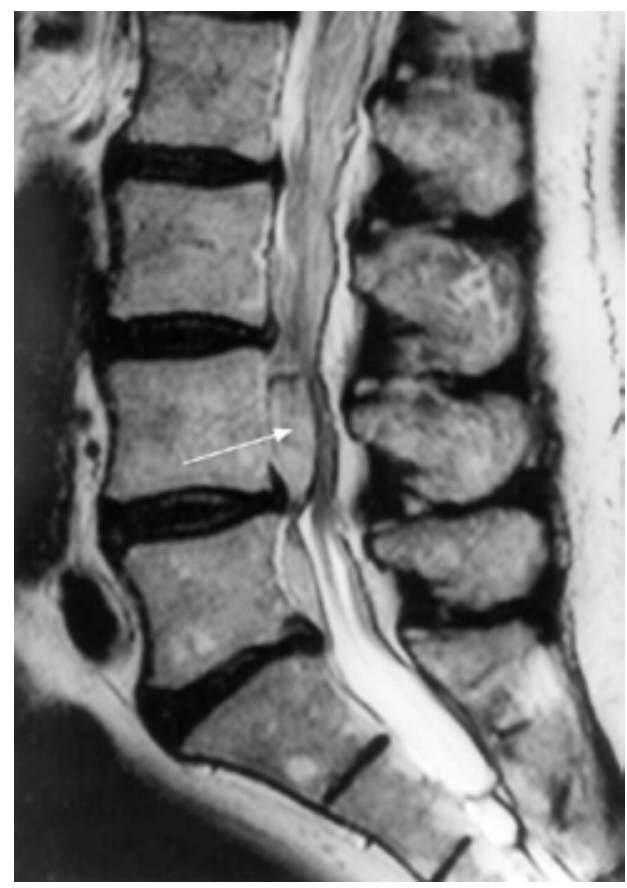

Figura 18. Imagen sagital potenciada en T2 que muestra la misma colección epidural de la figura 17. El hematoma es más difícil de visualizar por su alta señal. Se encuentra en estrecha relación con el disco intervertebral (flecha).

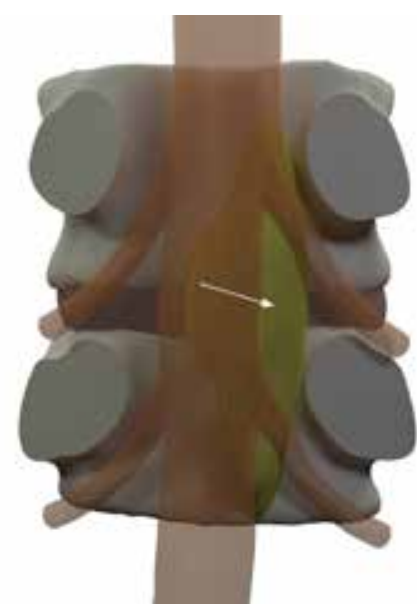

19a.

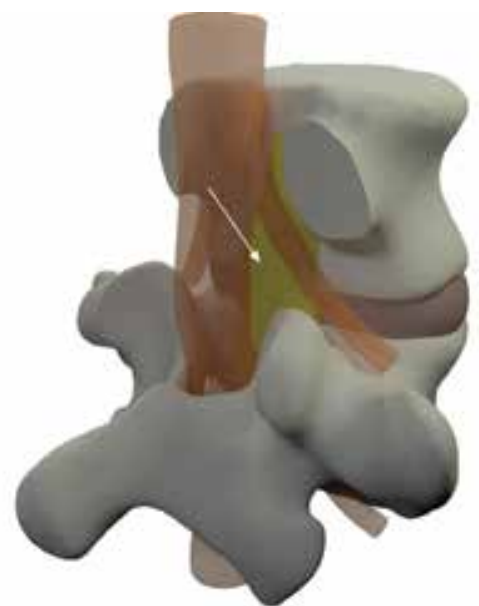

19b.

Figura 19. Representación de un absceso epidural anterior central y lateral derecho. En la vista posterior (19a) se visualiza que se extiende por detrás de los cuerpos vertebrales y disco intervertebral (flecha). En la vista posterolateral derecha (19b) se observa que deforma el saco dural y origen de las raíces (flecha). 


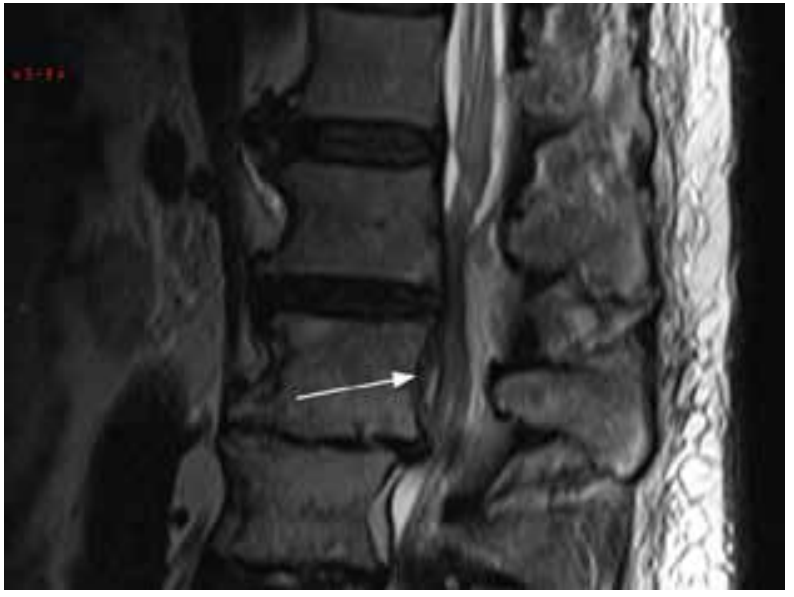

Figura 20. Imagen sagital potenciada en T2 que muestra una estenosis del canal raquídeo sin clara separación de los planos anotómicos. Se observa una colección por detrás del cuerpo vertebral (flecha), adyacente al disco que corresponde a un absceso epidural.

producido por una hernia discal en algunos casos (Figuras 19a, b).

Fue descrito hace más de 250 años por Giovanni Morgagni. Es infrecuente, se estima una incidencia entre 0,2-1,2 a 2,5-5 casos por 100.000 admisiones hospitalarias ${ }^{31}$.

Más frecuente en hombres entre los 50 y 70 años, pero afecta a todos los grupos etarios ${ }^{32}$.

Son factores de riesgo la diabetes mellitus, HIV, trauma espinal o cirugía espinal reciente, infección cutánea o del trato urinario, etc. ${ }^{33}$.

El Stafilococo Aureus es el patógeno más frecuentemente identificado, presente en el $70-90 \%$ de los casos.

Se presenta con lumbago, con un $50 \%$ de fiebre, radiculopatía y compromiso esfinteriano ${ }^{34}$.

La resonancia magnética es la técnica de elección en un paciente con lumbago con factores de riesgo y eventual fiebre. En las imágenes ponderadas en T1 el disco y cuerpo vertebral adyacente se observan de baja señal, con pérdida de la continuidad de sus márgenes. En las imágenes ponderadas en T2 hay mayor señal del cuerpo (Figura 20) y del disco comprometido ${ }^{35}$.

Se aconseja utilizar gadolinio (Figura 21), siempre que no esté contraindicado ${ }^{36}$.

Se describen 2 patrones de la captación de gadolinio (Gd) en $\mathrm{RM}^{37}$.

Etapa flegmonosa: Patrón de refuerzo homogéneo con el uso de Gd.

Etapa de absceso líquido: pus líquido, rodeada de cambios inflamatorios, los cuales se impregnan post Gd.

\section{Discusión}

La hernia discal es un diagnóstico frecuente en

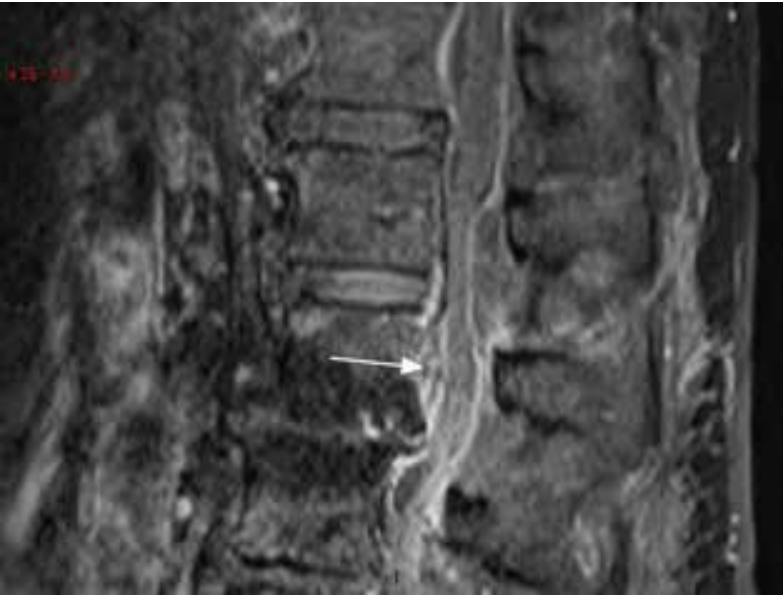

Figura 21. Imagen sagital ponderada en T1 con saturación grasa post contraste. Se observa una colección mal definida (flecha) con captación heterogénea por detrás del cuerpo vertebral y que desplaza el saco dural hacia posterior.

la práctica radiológica, sin embargo, debemos considerar éstas y otros diagnósticos imagenológicos que pueden simular una hernia discal.

\section{Bibliografía}

1. Garfin SR. Cervical degenerative disorders: Etiology, presentation, and Imaging studies. Instr Course Lect 2000; 49: 335-338.

2. Clark CR, Benzel EC, Currier BL, et al. The Cervical Spine, 4th ed. The Cervical Spine Research Society Editorial Committee. Philadelphia, PA: Lippincott Williams and Wilkins 2005.

3. Klimo P Jr, Schmidt MH. Surgical management of spinal metastases. Oncologist 2004; 9: 188-196.

4. Shah LM, Salzman KL. Imaging of Spinal Metastatic Disease. Int J Surg Oncol 2011; 769-753.

5. Hwang J, Park I, Kang DH, Jung JM, Discal Cyst of the Lumbar Spine. J Korean Neurosurg Soc 2008; 44: 262-264.

6. Toyama Y, Kamata N, Matsumoto M, et al. Pathogenesis and diagnostic title of intraspinal cyst communicating with intervertebral disk in the lumbar spine. Rinsho Seikei Geka 1997; 32: 393-400.

7. Kono K, Nakamura H, Inoue Y, Okamura T, Shakudo M, Yamada R. Intraspinal extradural cysts communicating with adjacent herniated disks: imaging characteristics and possible pathogenesis. AJNR Am J Neuroradiol 1999; 20: 1373-1377.

8. Chiba K, Toyama Y, Matsumoto M, Maruiwa H, Watanabe M, Nishizawa T. Intraspinal cyst Communicating with the Intervertebral disc in the lumbar spine: Discal Cyst. SPINE 2001; 26(19): 2112-2118.

9. Gibson MJ, Buckley J, Mawhinney R, et al. Magnetic resonance imaging and discography in the diagnosis of disc degeneration. J Bone Joint Surg 1986; 68B: 369-373.

10. Lee HK, Lee DH, Choi CG, Kim SJ, Suh DC, Kahng SK, et al: Discal cyst of the lumbar spine: MR imaging features. Clinical Imaging 2006; 30: 326-330. 
11. Tokunaga $M$, Aizawa $T$, Hyodo $H$, Sasaki $H$, Tanaka $Y$, Sato T: Lumbar discal cyst followed by intervertebral disc herniation: MRI findings of two cases. J Orthop Sci 2006; 11: 81-84.

12. Klekamp J, Samii M. Introduction of a score system for the clinical evaluation of patients with spinal processes. Acta Neurochir (Wien) 1993; 123: 221-223.

13. Conti P, Pansini G, Mouchaty H, Capuano C, Conti R. Spinal neurinomas: retrospective analysis and longterm outcome of 179 consecutively operated cases and review of the literature. Surg Neurol 2004; 61(1): 34-43.

14. Emamian S, Skriver E, Henriksen L, Cortsen M. Lumbar herniated disk mimicking neurinoma. Acta Radiologica 1993; 34(2): 127-129.

15. Kato T, George B, Mourier KL, Lot G, Gelbert F, Mikol J.Intraforaminal neurinoma in the lumbosacral region. Neurol Med Chir (Tokyo) 1993 Feb; 33(2): 86-91.

16. Saruhashi $Y$, Omura K, Miyamoto K, Katsuura A, Hukuda S. A migrated lumbar herniation simulating a dumbbell tumor. Journal of spinal disorders 1999; 12(4): 307-309.

17. Baker WM. Formation of synovial cysts in connection with joints. St. Bartholomews Hospital Reports 1885; 21: 177-190.

18. Kao CC. Lumbar intraspinal extradural ganglion cyst. J Neurosurg 1968; 29(2): 168-172.

19. Boviatsis EJ, Stavrinou LC, Kouyialis AT, Gavra MM, Stavrinou PC, Themistokleous M, et al. Spinal synovial cysts: pathogenesis, diagnosis and surgical treatment in a series of seven cases and literature review. Eur Spine J 2008 Jun; 17(6): 831-837.

20. Khalatbai K, Ansari H. MRI of degenerative cysts of the lumbar spine. Clinical Radiology 2008; 63: 322e-328.

21. Kouyialis AT, Boviatsis EJ, Korfias $S$ et al. Lumbar synovial cyst as a cause of low back pain and acute radiculopathy: A case report. South Med J 2005; 98: 223-225.

22. Resnick D. Degenerative diseases of the spine. In: Resnick D, editor. Bone and joint imaging. 2nd ed. Philadelphia: W.B. Saunders Company; 1996. p.355e77.

23. Doyle A, Merrilees M. Synovial Cysts of the Lumbar Facet Joints in a Symptomatic Population.Spine (Phila Pa 1976) 2004; 29(8): 874-878.

24. Wybier M. Imaging of lumbar degenerative changes involving structures other than disk space. Radiol Clin North Am 2001; 39: 101e14.

25. Trummer M, Flaschka G, Tillich M et al. Diagnosis and surgical management of intraspinal synovial cysts: report of 19 cases. J Neurol Neurosurg Psychiatry 2001 70: 74-77.

26. Liu SS, Williams KD, Drayer BP, et al. Synovial cysts of the lumbosacral spine: diagnosis by MR imaging. AJNR Am J Neuroradiol 1989; 10: 1239e42.

27. Mahallati $\mathrm{H}$, Wallace $\mathrm{CJ}$, Hunter KM, et al. MR imaging of a hemorrhagic and granulomatous cyst of the ligamentum flavum with pathologic correlation. AJNR Am J Neuroradiol 1999; 20: 1166e8.

28. Jackson R: Case of spinal apoplexy. Lancet 1869, 2: 5-6.

29. Domenicucci M, Mancarella C, Santoro G, Dugoni DE, Ramieri A, Arezzo MF,et al. Spinal epidural hematomas: personal experience and literature review of more than 1000 cases. J Neurosurg Spine 2017 Jun 2: 1-11.

30. van Aalst J, Rijkers K, Postma AA.Teaching Neurolmages: Posttraumatic lumbar epidural hematoma. Neurology 2015 6; 84(1): e7-8.

31. Sendi P, Bregenzer T, Zimmerli W. Spinal epidural abscess in clinical practice. Quarterly Journal of Medicine 2008; 101(1): 1-12.

32. Reihsaus e, Waldbaur $H$, Seeling W. Spinal epidural abscess: a meta-analysis of 915 patients. Neurosurgical Review 2000; 23(4): 175-204.

33. Darouiche RO. Spinal epidural abscess. New England Journal of Medicine 2006; 355(19): 2012-2020.

34. Adogwa O, Karikari IO, Carretal KR. Spontaneousspinal epidural abscess in patients 50 years of age and older: a 15-year institutional perspective and review of the literature. Journal of Neurosurgery: Spine 2014; 20(3): 344-349.

35. Pradilla G, Ardila GP, Hsu W, Rigamonti D. Epidural abscesses of the CNS. Lancet Neurol 2009; 8: 292300.

36. Sandhu FS, Dillon WP. Spinal epidural abscess: evaluation with contrast-enhanced MR imaging. AJNR Am J Neuroradiol 1991; 12: 1087-1093.

37. Numaguchi Y, Rigamonti D, Rothman MI, Sato S, Mihara F, Sadato N. Spinal epidural abscess: evaluation with gadolinium-enhanced MR imaging. Radiographics 1993; 13: 545-559, discussion 559-60. 